\title{
EDITORIAL EDIÇÃo ESPECIAL
}

\section{DO MANIFESTO ÁGIL À AGILIDADE ORGANIZACIONAL}

\section{From the agile manifesto to the organizational agility}

\author{
Rosária de Fátima Segger Macri Russo \\ Universidade Nove de Julho (UNINOVE) \\ romacrirusso@gmail.com \\ (D) Luciano Ferreira da Silva \\ Universidade Nove de Julho (UNINOVE) \\ Doutorado em Administração na Pontifícia Universidade Católica (PUC-SP) \\ If_silvabr@yahoo.com.br \\ Claudio Luis Carvalho Larieira \\ Universidade Presbiteriana Mackenzie / EAESP/FGV \\ larieira@ hotmail.com
}

\section{Cite como - American Psychological Association (APA)}

Russo, R. de F. S. G., Silva, L. F. da, \& Larieira, C. L. C. (2021, Ed. Esp. jan./abr.). Do manifesto ágil à agilidade organizacional. Editorial. Revista de Gestao e Projetos (GeP), 12(1), 1-10. https://doi.org/10.5585/gep.v12i1.19333.

Este editorial objetiva apresentar nossa edição especial comemorativa aos 20 anos do Manifesto Ágil. Aqui apresentamos algumas informações relevantes sobre o estado atual das práticas ágeis nas organizações no Brasil a partir de um levantamento desenvolvido pelos editores desta edição especial. Além disso, também apresentamos os artigos enviados e selecionados, dentre os vários enviados, que contribuem para a discussão do ágil no contexto empresarial e acadêmico.
Como comentado, para avaliar o panorama atual da utilização do método ágil nas organizações brasileiras, fizemos uma pesquisa ampla na qual obtivemos 202 respostas, com 124 válidas. Os respondentes em sua grande maioria (76\%) possuem no mínimo pós-graduação. Enquanto a grande maioria dos respondentes trabalha há mais de 10 anos com gestão de projetos (62\%), sua experiência em métodos ágeis é menor, dado que grande parte dos respondentes trabalha de 2 a 10 anos (49\%) com os 
métodos. Com relação ao tempo de adoção dos métodos ágeis, a grande maioria das organizações (76\%) ainda não tem 5 anos de adoção, apesar do Manifesto
Ágil ter mais de 20 anos, conforme pode ser visto na Figura 1.

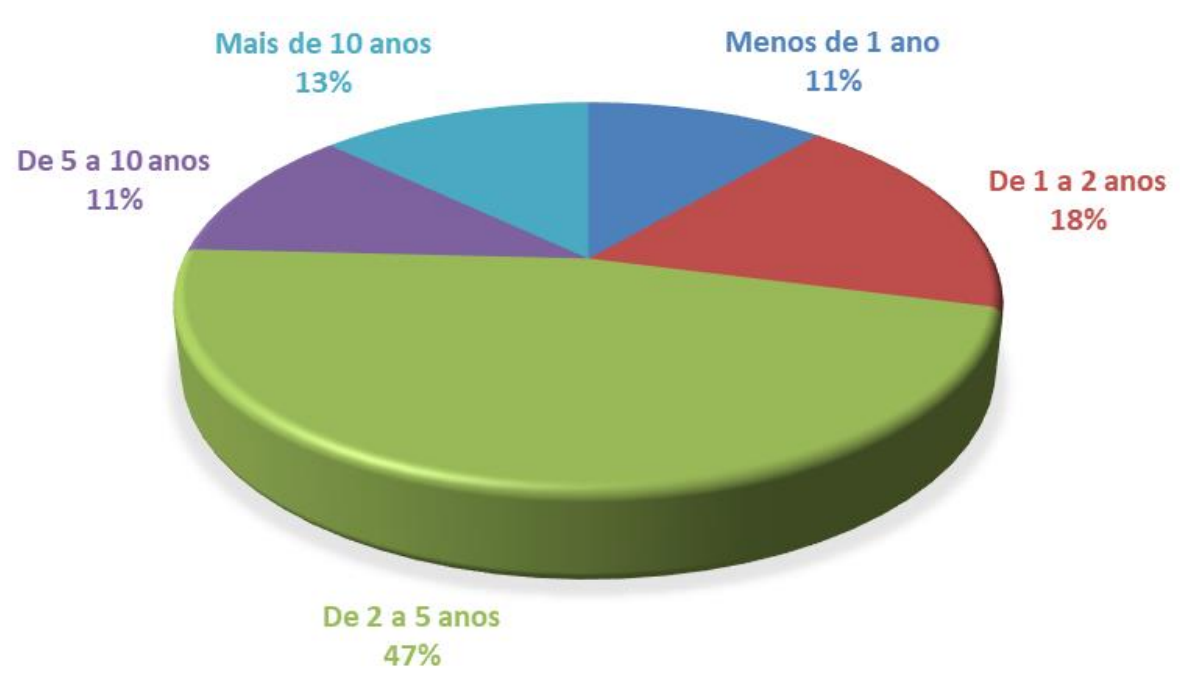

Figura 1 - Tempo de adoção dos métodos ágeis nas organizações Fonte: Elaborado pelos autores, 2021.

A Figura 2 mostra o nível de maturidade percebido pelos respondentes na organização na qual trabalha. $\mathrm{O}$ gráfico demonstra que as organizações participantes ainda estão caminhando para uma maturidade média na prática dos métodos, $38 \%$ considera que tem um bom nível de competência em alguns projetos e $28 \%$ se considera imatura. Provavelmente, este nível ocorre devido ao pouco tempo de adoção do método. Por outro lado, $26 \%$ das organizações se percebem como maduras, o que as permite uma maior adaptabilidade às mudanças do mercado. 


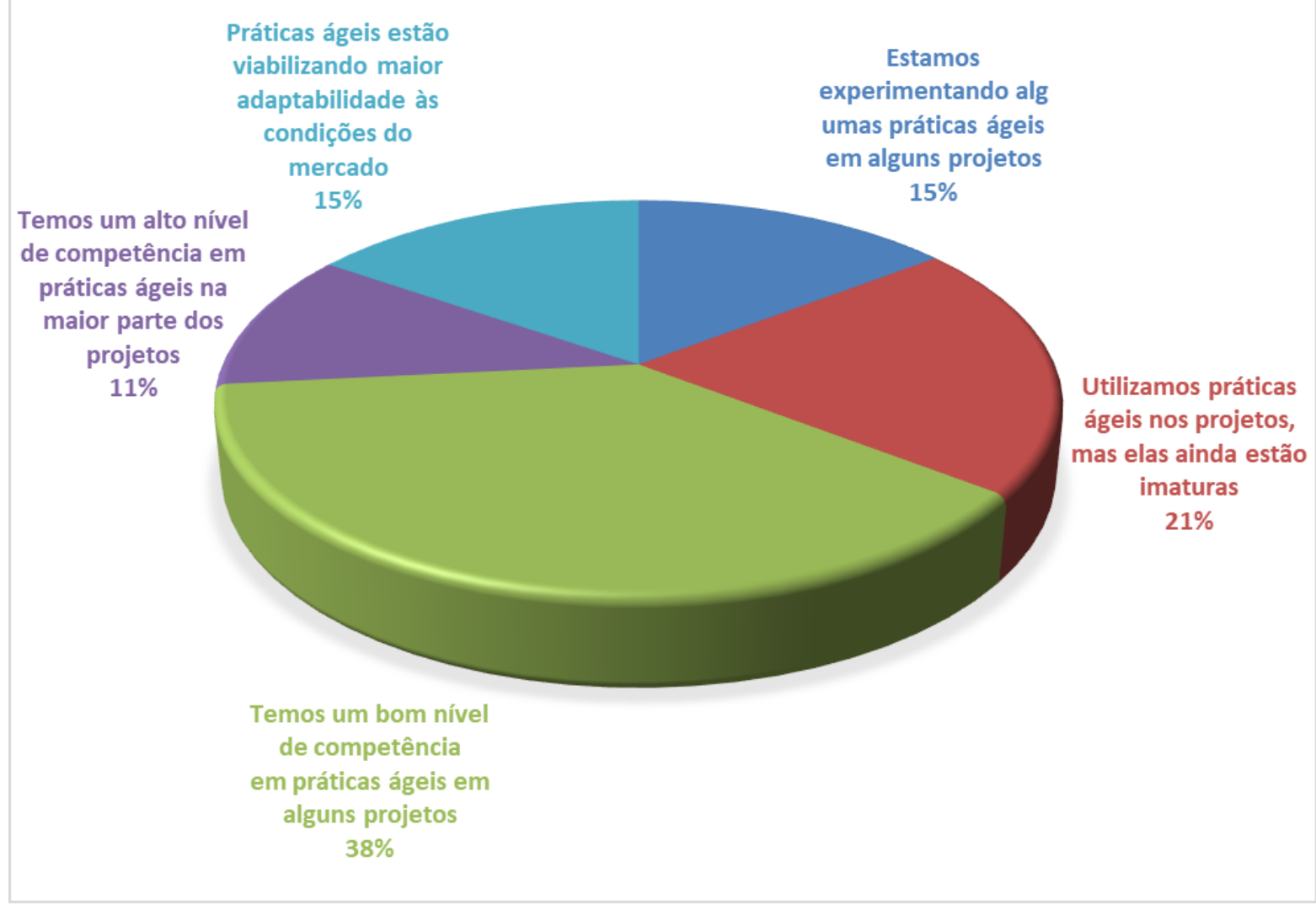

Figura 2 - Estágio de maturidade das práticas ágeis na organização.

Fonte: Elaborado pelos autores, 2021.

Podemos inferir que essa falta de maturidade nas organizações faz com que os colaboradores sejam treinados durante o desenvolvimento no projeto e não em cursos formais. A grande maioria dos treinamentos evidencia a opção pelo Scrum (62\%) e Kanban (15\%), sendo que muitos dos cursos foram realizados para obter certificações, demostrando uma preocupação dos profissionais em evidenciar o nível de conhecimento. Para métodos ágeis escalados foram citados apenas cursos sobre o Safe (14\%).
A questão sobre as competências necessárias aos gestores nos diferentes métodos é explorada nesta edição especial no artigo "As competências de gestores de projetos que atuam com métodos ágeis e tradicionais: Um estudo comparativo" de Maria Paula Novakoski Perides, Erika Borgonovo Barrote e Roberto Sbragia. O estudo apresenta as cinco competências consideradas mais importantes para os dois grupos estudados. Um aspecto relevante na pesquisa é que apesar da presença das mesmas competências convergirem 
quando adotadas as duas metodologias, estas competências são ordenadas de maneira distinta em cada uma delas. As competências evidenciadas são: Integridade e Confiabilidade Pessoal, Comunicação Pessoal, Trabalho em Equipe, Estratégia e Relacionamentos e Engajamento. Os autores apontam que a similaridade das respostas evidenciadas entre os grupos de profissionais que trabalham com métodos ágeis $\mathrm{e}$ abordagens mais tradicionais pode nos levar a questionar se as empresas estão conseguindo criar uma cultura organizacional que explora de fato as competências dos profissionais quando da adoção das abordagens ágeis.

Com relação a adoção do ágil podemos dizer que cada organização pode ter várias motivações. Como pode ser visto na Figura 3, a maioria (mais de 50\%) indicou que adotaram o ágil para acelerar a entrega dos produtos, atender melhor o cliente, melhorar o alinhamento entre o time de projetos e os demandantes e melhorar a habilidade de gerenciar mudanças de prioridades. Neste sentido podemos dizer que esses motivos levam em consideração atender as expectativas e necessidades dos demandantes do projeto, o cliente.

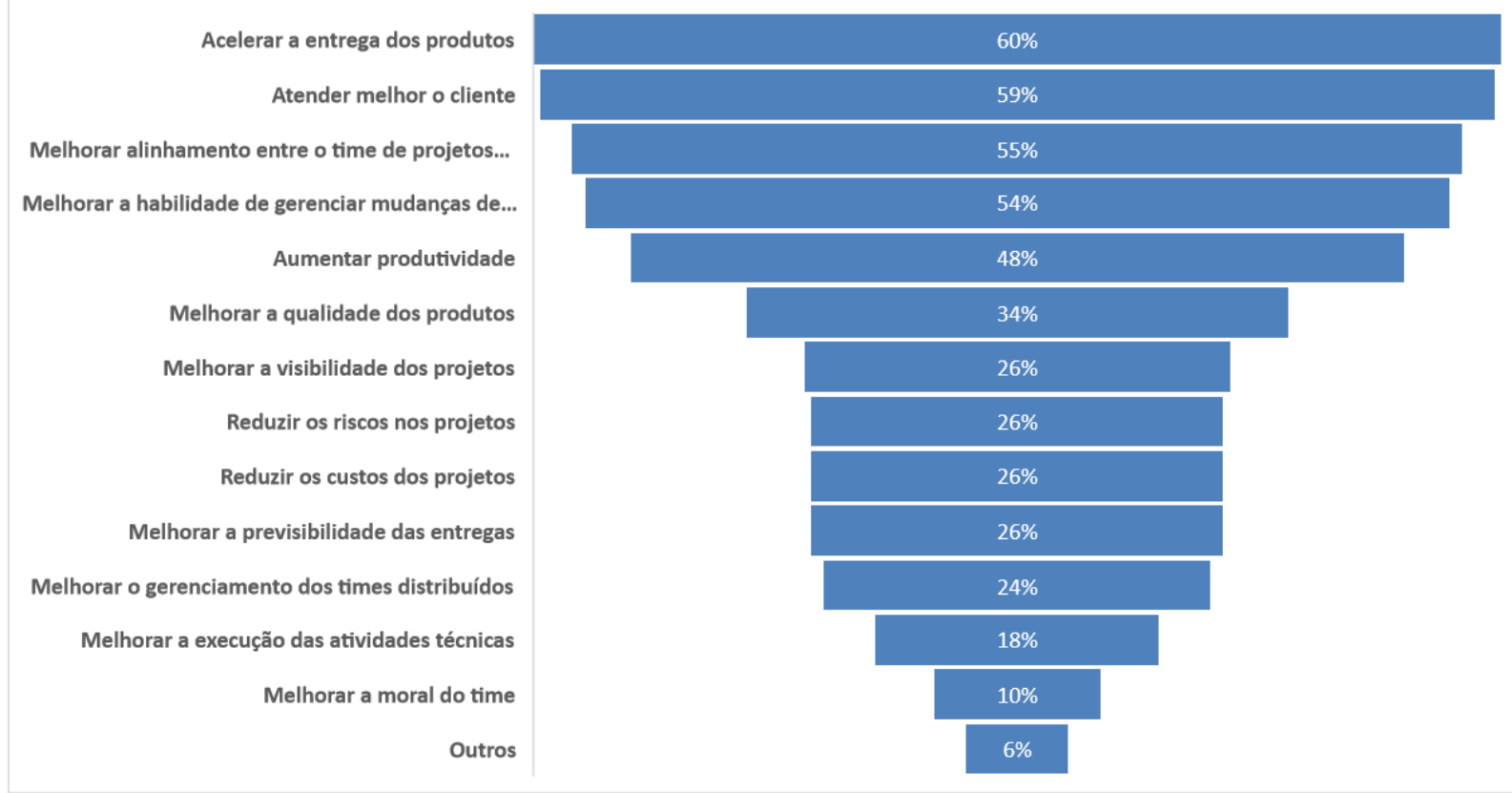

Figura 3 - Motivações para a adoção de práticas ágeis nas organizações. Fonte: Elaborado pelos autores, 2021.

Esse aspecto foi destaque no artigo "Colaboração com clientes e inovação aberta no desenvolvimento ágil de software: Uma revisão sistemática de literatura" de Taiana Beatriz Junkes da Silveira e Dannyela da Cunha Lemos. Elas 
demonstram a partir da intersecção dos tópicos colaboração com clientes, inovação aberta e metodologias ágeis que a maior participação dos clientes potencializa agregar valor ao produto dos projetos. Além disso, foi evidenciado nesse artigo que os clientes preferem se envolver em todas as fases, não somente no início como no estudo de usabilidade, ou ainda no final em sessões para teste beta do projeto. Este artigo permite uma discussão interessante sobre os benefícios da colaboração com os clientes no gerenciamento de projetos que adotam abordagens ágeis.

$\mathrm{Na}$ adoção do ágil, deve-se avaliar também qual o nível de aplicação do método ágil nos projetos. $\mathrm{Na}$ pesquisa realizada para esta edição foi demonstrado que muitas organizações adotam o método híbrido de gestão de projetos, utilizando em conjunto métodos ágeis e métodos tradicionais, também chamados de preditivos (ou Plan Driven), tendo como exemplo o PMBOK (67\%) do PMI e o Prince2 (3\%). . Entretanto, o percentual de projetos híbridos nessas organizações não é grande, pois $23 \%$ das organizações têm poucos projetos e $33 \%$ das organizações tem no máximo metade dos projetos híbridos.

O artigo "Processo de transformação ágil em uma empresa brasileira de Telecom" de Marcelo Luiz do Amaral Gonçalves, Ricardo Antônio Câmara da Silva, Eduardo André Cândido Silva e Renato Penha objetivou estudar uma empresa que decidiu mudar seu modelo de gerenciamento de projetos para se adequar às necessidades de mercado. Para tanto, esta empresa adotou um framework de gerenciamento e ferramentas ágeis no departamento de infraestrutura de TI. Os autores evidenciaram que o estágio de transição entre o modelo tradicional e o modelo ágil pode ser caracterizado como uma gestão híbrida de projetos. Eles identificaram que o framework adotado é aderente ao Modelo- $\mathrm{V}$ e que os processos da fase de execução que possuíam entregas particionadas adequaram-se às práticas e métricas ágeis. Por outro lado, as demais fases que exigiam maior controle ainda aplicam o modelo tradicional, vinculando processos obrigatórios e as exigências de documentação. Os autores ainda apresentam fatores facilitadores e barreiras ao processo de transformação ágil.

A importância ainda da utilização híbrida dos métodos e artefatos é explorada nesta edição especial no artigo “Gestão adaptativa de projetos: Um levantamento dos artefatos mais utilizados para gerenciar o escopo do projeto" de Ivete Rodrigues e Danilo Rabetti Correio. Este artigo 
apresenta, a partir de uma survey, os tipos de artefatos que estão sendo utilizados pelos gerentes de projetos para suportar o gerenciamento de escopo dos projetos quando adotados métodos preditivos e ágeis. Os autores identificam quais artefatos são mais utilizados pelos gerentes de projetos tendo em vista a complexidade dos projetos. Os resultados apontam para a oportunidade de utilizar diferentes artefatos para diferentes projetos com base em suas complexidades. Apesar de evidenciarem os artefatos aderentes aos métodos ágeis, os autores verificaram que os artefatos preditivos continuam sendo os mais utilizados, com apenas um artefato ágil entre os dez mais utilizados.

As organizações participantes da pesquisa realizada para a edição especial usam métodos ágeis em todo tipo de projeto, além de desenvolvimento de software, sendo os mais citados projetos de melhoria de processos, projetos de $\mathrm{RH}$, projetos de marketing, projetos de Business Agility e projetos de negócios. Essas organizações são em sua maioria da área de Tecnologia da Informação / Telecomunicações (32\%), seguida das empresas que tem atividades financeiras, de seguros e serviços relacionados $(29 \%)$ e indústrias de transformação $(6 \%)$. As demais estão distribuídas em vários segmentos como a indústria de extração que é estudada no artigo "Scrum and agility beyond it: Evidences in the Brazilian mining industry" de Mohamad Ismat Soueid e Antonio Felipe Cora Martins. Este artigo apresenta uma discussão sobre a aplicação de práticas de Scrum em uma empresa de minério brasileira, indústria de extração. Ele é relevante, pois discute agilidade em ambientes distintos dos de produção de software, estes mais aderentes à aplicação das práticas ágeis. Os autores deram foco no processo de capacitação de profissionais para compreender as potencialidades de aplicação dos princípios do Manifesto Ágil e práticas Scrum. Os resultados apontaram para aspectos positivos para o grupo estudado no relacionamento entre as pessoas (colaboração), maior proximidade do cliente no processo de entrega de valores (percepção do valor do produto), melhor comunicação e interatividade entre os membros da equipe, melhor priorização de tarefas (viabilidade), geração de novos produtos (inovação) e adoção de uma reunião retrospectiva ao final de cada ciclo de entrega como procedimento formal de melhoria contínua.

Ainda sobre a pesquisa realizada por nós, as respostas mostraram que apesar 
de $90 \%$ das organizações utilizar o método Scrum, o Kanban também é usado por $70 \%$ das empresas, mostrando que muitas delas usam mais de um método. Em termos de práticas adotadas, é interessante notar que nem todas adotam as práticas mais comuns:

- $90 \%$ fazem o planejamento de sprint/Iteração (sprint/iteration planning)

- $85 \%$ fazem reunião diária;

- $70 \%$ fazem a retrospectiva;

- $68 \%$ fazem a revisão da sprint/iteração e

- $58 \%$ tem product owner dedicado.

Essas práticas são exploradas nesta edição especial no artigo "Processos de aprendizagem em equipe de projeto que utiliza metodologia ágil" de Eduarda Vieira Floriani e Andrea Valéria Steil Correio que oportuna uma discussão sobre processo de aprendizagem de equipes em projetos que adotam metodologias ágeis. A partir de um estudo de caso em uma grande organização de TI do sul do Brasil, as autoras verificam a busca pelo conhecimento em reuniões diárias e de retrospectiva. A perspectiva teórica utilizada considerou a aprendizagem como o processo iterativo de comportamentos de reflexão-ação. Os resultados apontaram que os comportamentos de aprendizagem durante as reuniões predominantemente estavam vinculadas à reflexão (64\%) em detrimento da ação (36\%). Os resultados ainda indicaram que os comportamentos de reflexão promovem comportamentos de ação, sendo que há um sistema de retroalimentação de aprendizagem. Os autores apontam que a metodologia ágil facilita a promoção de comportamentos de aprendizagem, mas a sua adoção não garantirá que a aprendizagem de fato acontecerá.

Após a adoção e pleno uso dos métodos ágeis, é imporante avaliar se ele correspondeu às expectativas iniciais. A partir dos dados levantados por nós, comparou-se as motivações com os benefícios da adoção dos métodos ágeis, estes últimos apresentados na Figura 4. Com base nestes resultados, pode-se inferir que o nível de expectativas alcançado está abaixo do inicialmente esperado. Apenas o benefício de ter maior habilidade de gerenciar mudanças de prioridades foi alcançado por mais de $50 \%$ dos respondentes, bem próximo da expectativa inicial de 54\%. Dois itens que podemos destacar que alcançaram o nível das expectativas, apesar de serem baixas, são melhor previsibilidade das entregas e redução dos riscos nos projetos (26\%). 
Russo, R. de F. S. G., Silva, L. F. da, \& Larieira, C. L. C. (2021, Ed. Esp. jan./abr.). Do manifesto ágil à agilidade organizacional. Editorial

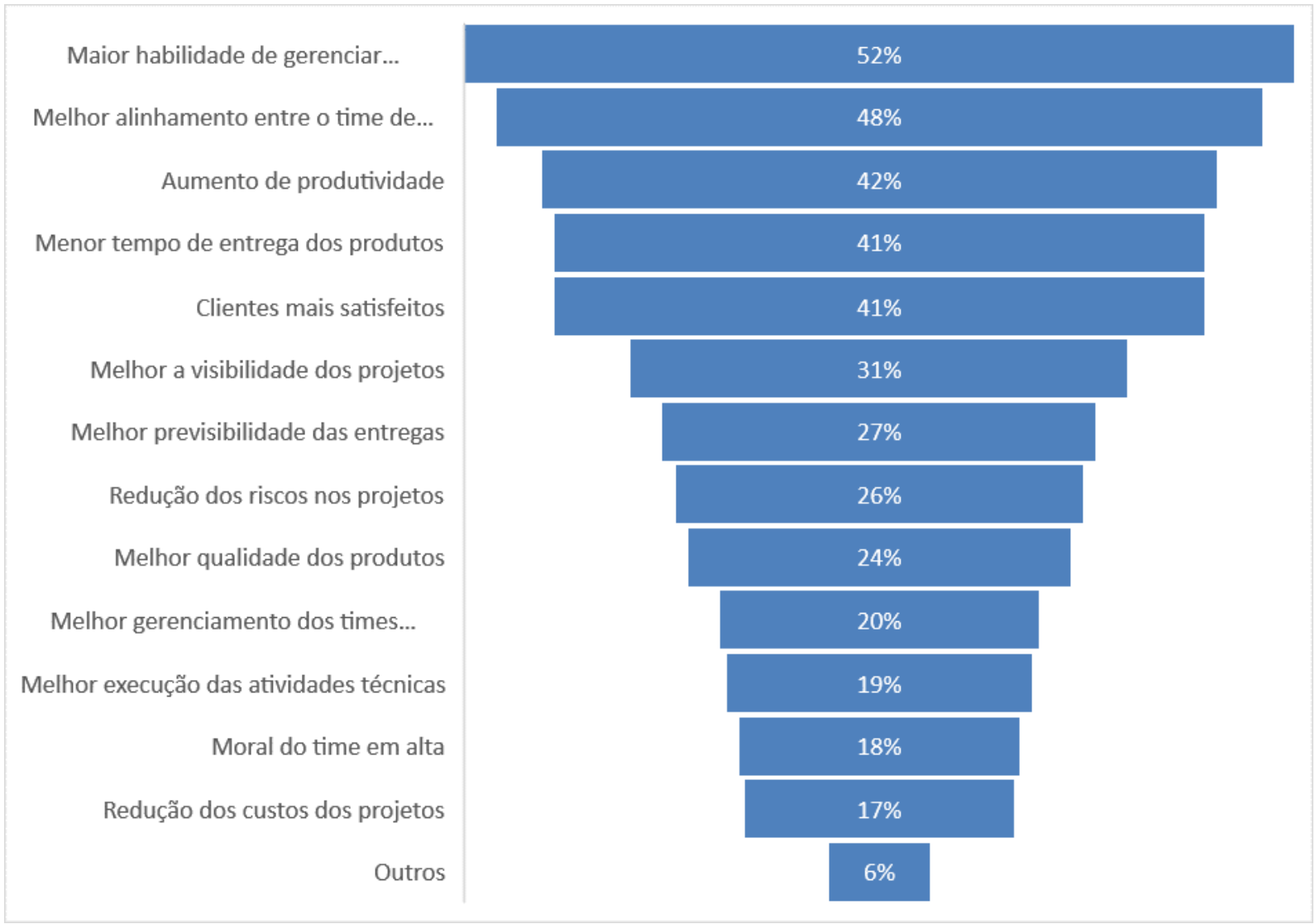

Figura 4 - Benefícios percebidos pela adoção de métodos ágeis. Fonte: Elaborado pelos autores, 2021.

Percebemos, pela pesquisa, que o tema de gestão de riscos, apesar de importante, ainda não é central quando se trata de métodos ágeis. Ele está em $5^{\circ}$ lugar como um motivo para a adoção de métodos ágeis e, consequentemente, a redução dos riscos ocupa o $8^{\circ}$ lugar nos benefícios obtidos com essa adoção. Em consonância com estes resultados, o artigo "O gerenciamento de riscos em projetos gerenciados por abordagens ágeis: Uma revisão sistemática da literatura" de Pedro Jose Martins Alvarez Fernandes e Roque
Rabechini Jr. promove uma discussão a partir de estudo exploratório sobre os riscos em estudos que tratam sobre as abordagens ágeis. Os autores verificaram que este campo de estudo ainda é incipiente, o que traz oportunidades para pesquisas. Os artigos analisados com maior profundidade no estudo tinham como principal objetivo propor um modelo para o gerenciamento de riscos em projetos gerenciados por abordagens ágeis. Por fim, muitos riscos identificados na revisão sistemática estão associados ao fator “pessoas", este que é um dos valores 
centrais da abordagem ágil, contrapondo os benefícios e as vantagens reconhecidas na literatura para esta abordagem.

Apenas 40 das 120 empresas que participaram da pesquisa realizada para esta edição especial utilizam métodos ágeis escalados. Dessas, $62 \%$ usa o Scaled Agile Framework (SAFe), 21\% usa Scrum of Scrums e $21 \%$ indicou que usa método criado internamente na organização. A barreira enfrentada pela maioria foi a falta de skills e experiências com métodos ágeis (59\%), a partir do que podemos inferir que o pouco tempo de adoção das organizações é uma causa de fragilidade. A cultura organizacional $(51 \%)$ e a resistência às mudanças $(41 \%)$, que estão em desacordo com os valores ágeis, também trazem desafios para a adoção dos métodos ágeis escalados.

O artigo "Desafios da aplicação do ágil escalado em projetos de software: Estudo de caso em uma organização financeira" de Leonardo Augusto Feitosa e Wagner Solivan Ferreira publicado em nossa edição especial traz a oportunidade de discutir os problemas sobre escalar ágil nas empresas. Os autores indicam que apesar da empresa já desenvolver projetos que adotam a abordagem ágil, sendo este inclusive um ambiente propicio para ágil escalado, a empresa ainda enfrenta dificuldades para tal ação. Os resultados apontam para problemas relacionados à complexidade e à duração dos projetos. Alguns dos desafios encontrados na empresa estudada se originam da inclusão de trabalhos não planejados, oriundo de agências reguladoras, e questões relacionadas à gestão de pessoas como a gestão de cargos e o sistema de remuneração. Tópicos alinhados com as respostas da pesquisa quanto ao problema de cultura organizacional.

Apesar do tema ágil ser discutido há mais de 20 anos, percebemos que a adoção pelas empresas ainda é recente. Ainda que o método tenha sido originado na área de desenvolvimento de software, ele já permeia todos os tipos de projetos, mesmo em segmentos de negócios tradicionais, nos quais métodos preditivos de gestão de projetos são vistos como mais adequados.. Nessa análise inicial da pesquisa, percebe-se que ainda falta maturidade nas organizações, além de pesquisas que revelem qual o tipo de método e a forma de aplicação mais indicada em cada projeto: tradicional, ágil ou híbrido. Recebemos poucas pesquisas sobre o ágil escalado, demonstrando que a análise da utilização do ágil nos vários níveis da organização ainda precisa ser aprofundado. 
A leitura dos artigos desta edição especial poderá esclarecer vários pontos e ao mesmo tempo indicar novas pesquisas para nos aprofundarmos mais e entendermos melhor porque adotar e como implantar os métodos ágeis em todos os níveis organizacionais. Causas que impeçam que as motivações da adoção do ágil sejam alcançadas também precisam ser esclarecidas para que as organizações possam ser mais bem sucedidas na gestão de projetos, o que movimenta bilhões na economia. 